Research Note

Journal of Extension Education

Vol. 30 No. 2, 2018

DOI:https://doi.org/10.26725/JEE.2018.2.30.6079-6082

\title{
Perceived Level of Importance and Competency of Agricultural Extension Officers in Agriculture and Allied Activities
}

\author{
Khalilullah Panjshiri ${ }^{1}$, N. Sriram ${ }^{2}$ and P. Suganthkumar ${ }^{3}$
}

\begin{abstract}
Training is the process of assisting a person for enhancing one's efficiency and effectiveness at work. A study was conducted in Coimbatore district of Tamil Nadu to ascertain the perceived importance and competency of agriculture extension officials and their training needs. The first six ranked training needs of the respondents in the study area were found to be integrated nutrient management, integrated water management, integrated weed management, agricultural waste management, organic farming and integrated pest management.
\end{abstract}

Keywords: Training need; Extension officers; Competency

Training has been recognized as an important input in improving the professional competence of extension personnel for effective transfer of technology to the farming community.

Thesuccessofagricultural extension and its role in agricultural development doesn't stop its ability to transfer knowhow to farmers, but also on its capacity to create active and positive interactions between agriculture and the other officials involved in the process of agricultural development in order to understand and learn from practice and help them identify and clarify where the needs and experience (Saleh, et al., 2015). Training in any form is intrinsic to organizational effectiveness and efficiency. The study was conducted to ascertain the perceived importance and competency of agriculture extension officials and their training needs.

\section{METHODOLOGY}

The study was conducted in Coimbatore district of Tamil Nadu. Random sampling was used to select 70 respondents from Coimbatore district. Block level extension officials were selected which includes Assistant Director of Agriculture, Deputy Agricultural Officer, Agricultural Officer and Assistant Agricultural Officers. All the thirteen extension workers of these blocks were selected as sample for the study. A Mean Weighted Discrepancy Score (MWDS) was calculated to describe overall rankings for each of the

1. Extension official, Directorate of Agriculture, Parwan Province, Jangalbagh, Afghanistan 2. Associate Professor and 3. PG Scholar, Department of Agricultural Extension and Rural Sociology, TNAU, Coimbatore, Tamil Nadu, India

Received : 28-06-2018; Accepted : 04-07-2018 
competencies. To determine the Mean Weighted Discrepancy Score (MWDS), the following statistical methods were used: A discrepancy score was calculated for each individual on each competency by taking the importance rating minus the ability (competency) rating. A weighted discrepancy score was then calculated in each individual for each of the professional competency by multiplying the discrepancy score by the mean importance rating. A mean weighted discrepancy score for each of the competencies was calculated by taking the sum of the weighted discrepancy scores and dividing by the number of observations. Using the mean weighed discrepancy scores, the competencies were then ranked and the area of training need by the farmers was found.

\section{FINDINGS AND DISCUSSION}

Extension officers' overall perceived level of importance of agriculture and allied activities

The overall perceived level of importance of agriculture and allied activities of the respondents were calculated and analyzed and presented in Table 1. By using mean and standard deviation the respondents were categorized in to three categories.

Table 1.

Extension Officers' overall perceived level of Importance and Competency of Agriculture and allied activities

\begin{tabular}{|c|c|c|c|}
\hline SI.No. & Category & Frequency & Percentage \\
\hline \multicolumn{4}{|c|}{ Extension officers' perceived level of importance of agriculture and allied activities } \\
\hline 1 & Low & 15 & 21.40 \\
\hline 2 & Medium & 42 & 60.00 \\
\hline 3 & High & 13 & 18.60 \\
\hline \multicolumn{4}{|c|}{ Extension officers' perceived level of competency of agriculture and allied activities } \\
\hline 1 & Low & 14 & 20.00 \\
\hline 2 & Medium & 44 & 62.90 \\
\hline 3 & High & 12 & 17.10 \\
\hline
\end{tabular}

It is found from Table 1 that three-fifths (60.00\%) of the respondents had perceived up to medium level on importance of agriculture and other allied activities for their job followed by 21.40 per cent and 18.60 per cent of the respondents had medium and high level.
Extension officers' overall perceived level of competency of agriculture and allied activities

It is found from the table that more than three-fifths $(62.90 \%)$ of the respondent had perceived up to medium level on competency of agriculture and other allied 
activities for their job followed by 20.00 per cent and 17.10 per cent of the respondents who had medium and high levels respectively.

\section{Training needs of the respondents}

The ranking of training needs is given in Table 2.

Table 2.

Training needs of the respondents

\begin{tabular}{|c|l|c|c|}
\hline SI. No. & \multicolumn{1}{|c|}{ STATEMENT } & MWDS & RANK \\
\hline 1 & Integrated nutrient management & 2.235129 & 1 \\
\hline 2 & Integrated water management & 2.093076 & 2 \\
\hline 3 & Integrated weed management & 1.996622 & 3 \\
\hline 4 & Agricultural Waste management & 1.915744 & 4 \\
\hline 5 & Organic farming & 1.771064 & 5 \\
\hline 6 & Integrated pest management & 1.745168 & 6 \\
\hline 7 & Post-Harvest Management & 1.646275 & 7 \\
\hline 8 & Marketing intelligence & 1.469319 & 8 \\
\hline 9 & Farm Crop Management / crop planning & 1.419779 & 9 \\
\hline 10 & Integrated disease management & 1.407394 & 10 \\
\hline 11 & Nursery Management & 1.320698 & 11 \\
\hline 12 & Agro forestry & 1.231188 & 12 \\
\hline 13 & Integrated farming system & 1.122162 & 13 \\
\hline 14 & Farm mechanization & 0.697692 & 14 \\
\hline 15 & Soil Health Management & 0.57797 & 15 \\
\hline 16 & New extension methods (Farmers' Field School, Farm & 0.477951 & 16 \\
\hline 17 & School etc.,) & 0.404579 & 17 \\
\hline 18 & Drought Management / Dry farming & 0.118596 & 18 \\
\hline 19 & Seed production technologies & 0.05067 & 19 \\
\hline 20 & ICT applications in Agriculture & 0.05611 & 20 \\
\hline 21 & Farmers' organization & 0.2721 & 21 \\
\hline & Managerial Skills & & \\
\hline
\end{tabular}

From the table, it is found that the first six training needs according to Mean Weighed Discrepancy Score were integrated nutrient management, integrated water management, integrated weed management, agricultural waste management, organic farming, and integrated pest management. Organic farming is also gaining momentum among farmers and other stakeholders for getting chemical free agricultural commodities. Hence, the extension workers should upgrade their knowledge and skill through training programmes. 
Majority of the respondents required training both in knowledge and skill level in the areas like allied enterprises, integrated nutrient management, integrated water management, integrated weed management, agricultural waste management, organic farming, and integrated pest management. So it is proposed that suitable trainings should be organized and imparted in the above mentioned areas so as to improve the knowledge and skill of the change agents.

\section{REFERENCES}

Rohit, J \& Beevi, C.N.A. (2017) Training need assessment on communication competencies of extensionists working in Krishi Vigyan Kendras (Farm Science centres) Journal of Extension Education, 29(3)

Saleh, J. M., Man, N., Lafta, A. H., Saleh, M. H., Hassan, S., Nawi, N. M., \& Kshash, B. H. (2016). A review: Training requirement of agriculture extension officers in Iraq. Asian Journal of Applied Sciences, 9(2), 34-40. 